3 Johanson WG, Seidenfeld JJ, Gomez P, De Los Santos R, Coalson JJ. Bacteriologic diagnosis of nosocomial pneumonia following prolonged mechanical ventilation. Am Rev Respir Dis 1988;137:259-64.

4 Van Deventer SJH, Buller HR, tenCate JW, Sturck A, Pauw W. Endotoxinaemia: an early predictor of septicaemia in febrile patients. Lancet 1988;i:605-8.

5 Stumacher RJ, Kovnat MJ, McCabe WR. Limitation of the usefulness of the limulus assay for endotoxin. $N$ Engl $J$ Med 1973;288:1261-4.

6 Elin RJ, Hosseini J. Clinical utility of the limulus amebocyte lysate (LAL) test. Progr Clin Biol Res 1985;189:307-27.

7 Pugin J, Auckenthaler R, Mili N, Janssens JP, Lew PD, Suter PM. Diagnosis of ventilator-associated pneumonia by bacteriologic analysis of bronchoscopic and non- bronchoscopic "blind" bronchoalveolar lavage fluid. $\mathrm{Am}$ Rev Respir Dis 1991;143:1121-9.

8 Gastinne H, Wolff M, Lachatre G, Boiteau R, Savy FP. Antibiotic levels in bronchial tree and serum during selective digestive decontamination. Intens Care Med 1991;17:215-8.

9 Smith BR, LeFrock JL. Bronchial tree penetration of antibiotics. Chest 1983;83:904-8.

10 Chastre J, Fagon J-Y, Soler P, Bornet M, Domarty Y, Trouillet JL, et al. Diagnosis of nosocomial bacterial pneumonia in intubated patients undergoing ventilation: comparison of the usefulness of bronchoalveolar lavage and protected specimen brush. Am J Med 1988;85:499506.

\title{
Surgery at the Brompton Hospital in 1932-3
}

I spent one year, November 1932 to November 1933, as the surgical resident at the Brompton Hospital, though at that time I was committed to a career in medicine, having within the previous 12 months become an MRCP and proceeded to $M D$ while working at the hospital in medical jobs at what would now be SHO level. It may seem odd that a post that would now be earmarked for trainee surgeons, and much sought after by those aiming for a specialised career in surgery, was then held by an aspiring physician. In the early 1930s the work at the Brompton, which had been founded as a hospital for consumption but had spread its interests to include chest diseases generally, was predominantly medical. Surgical intervention in chest disease had expanded only in the previous 10 years from little more than draining of empyemas to increasing use of various collapse procedures in pulmonary tuberculosis and of surgery within the open thorax, which had become a practicable proposition as a result of advances in anaesthesia based on experience in the first world war. In the late 1920 s lobectomy by a rather crude "snare" technique had been introduced in the treatment of localised bronchiectasis, and began to be attempted for a few cases of lung cancer. Removal of mediastinal tumours had become acceptably safe. Chronic empyema and lung asbscess were frequent problems. Surgical procedures required to deal with chronic empyema might be complex and formidable. External drainage was often considered an option in the treatment of lung abscess, and was a two stage procedure, requiring the preliminary production of pleural adhesions.

Because facilities for this sort of surgery were limited to specialist centres, many rare and complex cases were referred to the Brompton for consideration of surgical treatment. The two surgeons, JEH Roberts and Tudor
Edwards, were the leaders of thoracic surgery in London. They shared 30 surgical beds and one junior resident. Until 1935 the title of this post was assistant resident medical officer, and the holder of it was a physician in training. It was because it offered the possibility of experience of such a wide range of clinical problems, and because it seemed to me that it was the surgeons rather than the physicians who were moving into new territory, that I took the post.

The year for which I held this post was perhaps the busiest of my life. I was solely responsible for preoperative investigation, operative assistance, and, with the surgical ward sister, postoperative care as well as record keeping for the patients in 30 very active surgical beds, plus the not inconsiderable number under the care of the surgeons in the paying patients' wards. There was no one at what would now be surgical registrar or senior registrar level. There was no specialised postoperative or intensive care area, all patients returning directly from the theatre to the ward, where the surgical ward sister was a key figure; without her the entire set up would have collapsed. At the beginning of the year the two surgeons each had a voluntary clinical assistant-Clem Price Thomas for Tudor Edwards and Tim Nelson for JEH Roberts. During the year these were elected to the staff as assistant surgeons, so that I had four surgeons to look after. My successor in this post developed pulmonary tuberculosis towards the end of his year. I do not know how far this influenced the decision, when eventually in 1935 it was recognised that this job was one for a trainee surgeon, that two resident surgical officers were needed to do the work previously done by one assistant resident medical officer! 